\title{
Using a mixed-method approach to understand older adults' liking and potential barriers to consumption of oral nutritional supplements
}

\author{
O. B. Kennedy ${ }^{1}$, L. Methven ${ }^{1}$, K. Rahelu ${ }^{1}$, N. Economou ${ }^{1}$ and M. A. Gosney ${ }^{2}$ \\ ${ }^{1}$ Dept of Food Biosciences and ${ }^{2}$ Institute of Health Sciences, University of Reading, Reading RG6 6AP, UK
}

Oral nutritional supplements (ONS) are frequently wasted, with documented reasons including disliking the taste, texture or sweetness and feeling sick or bloated after drinking them ${ }^{(1)}$. The aim of the present study was to use a mixed methods approach (quantitative and qualitative) to investigate ONS acceptability and factors affecting their consumption by older healthy adults.

The perceived sweetness of four commercial vanilla ONS products (Abbott Ensure Plus (Abbott Nutrition, Maidenhead, Berks., UK), Nestle Clinutren (Nestle Nutrition, Croydon, Surrey, UK), Nestle Resource (Nestle Nutrition) and Nutricia Fortisip (Nutricia Ltd, Trowbridge, Wilts., UK)) was quantified by older adults ( $n$ 32; age range 62-88 years) using a 100 mm unstructured line scale. No individual was a regular consumer of any of the products. The liking of the products was quantified using a nine-point hedonic scale (1, dislike extremely; 9, like extremely). The qualitative research took the form of five focus groups, consisting of six to eight volunteers. A topic list devised from previous literature was used to guide the discussions and various commercial and trial ONS were presented as stimuli $^{(1)}$. The dialogue was tape-recorded, transcribed verbatim and thematically content analysed.

\begin{tabular}{|c|c|c|c|c|c|c|c|c|}
\hline \multirow{2}{*}{$\begin{array}{l}\mathrm{N} \\
\text { Attribute }\end{array}$} & \multicolumn{2}{|c|}{ Abbott Ensure Plus 32} & \multicolumn{2}{|c|}{ Nestle Clinutren 32} & \multicolumn{2}{|c|}{ Nestle Resource 32} & \multicolumn{2}{|c|}{ Nutricia Fortisip* 15} \\
\hline & Mean & $\mathrm{SD}$ & Mean & $\mathrm{SD}$ & Mean & $\mathrm{SD}$ & Mean & $\mathrm{SD}$ \\
\hline Sweetness & $65^{\mathrm{b}, \mathrm{c}}$ & 20.5 & $68^{\mathrm{a}, \mathrm{b}}$ & 25.2 & $56^{\mathrm{c}}$ & 24.9 & $79^{\mathrm{a}}$ & 14.9 \\
\hline Liking & $5.3^{\mathrm{b}}$ & 2.2 & $5.2^{\mathrm{b}}$ & 2.4 & $3.8^{\mathrm{a}}$ & 2.2 & 3.0nd & 2.0 \\
\hline
\end{tabular}

nd, Significance not determined. ${ }^{\mathrm{a}, \mathrm{b}}$ Mean values within the same row with different superscript letters were significantly different (for parametric sweetness data as determined by Fisher's least significant difference and for non-parametric liking data as determined by Nemenyi's procedure; $P<0.05$ ).

There was a significant difference in perceived sweetness of the four commercial products $(P=0.013)$ and mean liking also differed significantly between samples $(P=0.009)$, Liking and perceived sweetness were not correlated. Themes arising from the focus groups implied that sensory attributes such as sweetness, mouth feel and after taste negatively impacted on consumers' acceptability and willingness to consume the products: 'All too sweet and taste left I could not get rid of.' (female, aged 74 years); 'Left nasty taste all day, horrible.' (female, aged 77 years); 'If that what cures malnutrition, I'll die of malnutrition.' (male, aged 62 years).

The liking scores of commercial vanilla ONS were considered low, although not directly related to perception of sweetness. The focus group discussion corroborated previous studies, in which consumers thought that the taste of the products was the most important factor affecting consumption. The affect of flavour and mouth-feel attributes that lingered after consumption was a problem highlighted by a number of volunteers.

1. Gosney M (2003) $J$ Adv Nurs 43, 275-280. 